\title{
Trends in Organ Donation and Transplantation in the United States, 1999-2008
}

\author{
R. A. Wolfe ${ }^{a, *}$, E. C. Roys ${ }^{a}$ and R. M. Merion ${ }^{a, b}$ \\ a Scientific Registry of Transplant Recipients, Arbor \\ Research Collaborative for Health, Ann Arbor, MI \\ b Scientific Registry of Transplant Recipients, University \\ of Michigan, Ann Arbor, MI \\ * Corresponding author: Robert A. Wolfe, \\ robert.wolfe@arborresearch.org \\ Note on sources: The articles in this report are based on \\ the reference tables in the 2009 OPTN/SRTR Annual \\ Report. Table numbers are noted in brackets and may be \\ found online at: http://ustransplant.org.
}

Key words: Allocation, graft survival, OPTN, organ donation, patient survival, SRTR, transplantation, waiting list

Received 30 September 2009, revised 14 December 2009 and accepted for publication 18 December 2009

\section{Introduction}

This overview of solid organ transplantation in the United States is produced as part of the 2009 OPTN/SRTR Annual Report. The Scientific Registry of Transplant Recipients (SRTR) prepares the Annual Report in collaboration with the Organ Procurement and Transplantation Network (OPTN) under contract with the Health Resources and Services Administration (HRSA). The report contained herein was prepared by the Arbor Research Collaborative for Health, which, with the University of Michigan, is the contractor for the SRTR.

This report reviews many aspects of solid organ transplantation to provide a resource for patients, the transplant community, the public and the federal government. It features 10 articles showcasing specific topics in solid organ transplantation. Experts in the field of transplantation contributed to each article, offering a comprehensive look at the current state of transplantation and trends over the past decade.

Text and figures are drawn from recent SRTR analyses and reference tables of the 2009 Annual Report. Those reference tables may be accessed online at the SRTR and OPTN websites (www.ustransplant.org and optn.transplant.hrsa.gov), along with the articles presented here.

\section{Summary Statistics on Organ Transplantation in the United States}

At the close of 2007, 183222 persons were recorded in available OPTN data as living with a functioning transplanted organ [Table 1.14]. This reflects an increase of $1.7 \%$ over 2006 and a 56.6\% increase since 1999.

The total number of organs transplanted decreased from 27586 in 2007 to 27281 in 2008 . This was an overall decrease of 305 organs transplanted $(1.1 \%)$, including 91 (1.4\%) fewer living donor transplants (Table 1). The number of deceased donor kidney transplants increased by only $0.2 \%$, while living donor kidney transplants dropped by $1.2 \%$. A decrease of $1.1 \%$ was observed in deceased donor liver transplants in 2008. There was a corresponding $1.57 \%$ overall decrease in the number of organs recovered for transplant during this time period (Table 2).

Table 3, which includes patients listed at both active and inactive status, shows the 1-year change in the number of patients on the waiting list for each organ. At the end of 2008, 100597 people were registered on organ waiting lists $(67470$ active, 33120 inactive and 7 of unknown status). This reflects a $3.8 \%$ increase over the number of people waiting for an organ at the end of 2007 [Table 1.4]. There were 25465 patients listed as inactive status on the kidney waiting list at the end of 2008. The percentage of patients who were inactive on the kidney waiting list at the end of each year has increased from $10 \%$ in 2003 to $33 \%$ in 2008 [Tables 5.1a and 5.1b]. This increase might be largely attributed to policy implemented in 2003, which allows accrual of waiting time during inactive status (http:// optn.transplant.hrsa.gov/PoliciesandBylaws2/policies/pdfs /policy_7.pdf. See policy 3.5.11.1) (1).

The kidney waiting list grew $6.3 \%$, while the liver waiting list decreased $3.4 \%$, and the lung waiting list decreased $8.8 \%$. The size of the waiting list is influenced by many factors, including listing practices, donation rates, death rates and allocation policy.

Patient survival after transplant is recognized as an important metric for evaluating transplantation success. 
Table 1: Change in number of transplanted organs, 2007-2008

\begin{tabular}{lrrr}
\hline Transplanted organs & 2007 & 2008 & \% change \\
\hline Total & 27586 & 27281 & -1.1 \\
Deceased donor & 21279 & 21065 & -1.0 \\
Living donor & 6307 & 6216 & -1.4 \\
Kidney & 16120 & 16067 & -0.3 \\
Deceased donor & 10082 & 10101 & 0.2 \\
Living donor & 6038 & 5966 & -1.2 \\
Pancreas & 1215 & 1161 & -4.4 \\
PTA & 108 & 122 & 13.0 \\
PAK & 259 & 214 & -17.4 \\
Kidney-pancreas & 848 & 825 & -2.7 \\
Liver & 5890 & 5817 & -1.2 \\
Deceased donor & 5629 & 5568 & -1.1 \\
Living donor & 261 & 249 & -4.6 \\
Intestine (deceased donor) & 57 & 69 & 21.1 \\
Heart (deceased donor) & 2143 & 2085 & -2.7 \\
Lung & 1461 & 1473 & 0.8 \\
Deceased donor & 1458 & 1473 & 1.0 \\
Living donor & 3 & - & $\mathrm{n} / \mathrm{a}$ \\
Heart-lung & 31 & 26 & -16.1 \\
\hline
\end{tabular}

Source: 2009 OPTN/SRTR Annual Report, Table 1.7.

Table 4 shows the percentage of transplant recipients still alive 1 and 5 years after transplantation, by organ. The '1-year survival' cohort consists of recipients transplanted in 2006-2007, while the '5-year survival' cohort is based on recipients transplanted in 2002-2005. These are the most recent cohorts for which adequate follow-up data are available. One-year patient survival was above $90 \%$ for transplants involving deceased and living donor kidney alone, kidney-heart, kidney-pancreas, pancreas after kidney (PAK) and pancreas transplants alone (PTA). One-year patient survival following kidney-liver transplant was lower (87.4\%). Patient survival was lowest for liver-intestine transplants (63.3\%), plausibly due to the greater burden of disease for patients receiving the multi-organ transplant.

Table 5 shows graft survival by organ at 1 and 5 years after transplantation. Graft survival was calculated using the same cohorts as patient survival (Table 4). Over 90\% of kidneys transplanted alone or in combination with other organs were functioning 1 year after transplantation, except for those used in kidney-liver and kidney-heart transplants, of which $83 \%$ and $88 \%$ were still functioning after 1 year, respectively. Some patients survived organ failure by re-

Table 2: Change in number of recovered organs, 2007-2008

\begin{tabular}{lrrr}
\hline Recovered organs & 2007 & 2008 & \% change \\
\hline Total & 28405 & 27958 & -1.57 \\
Kidney & 14381 & 14274 & -0.74 \\
Pancreas-all & 1932 & 1830 & -5.28 \\
Liver & 7025 & 6832 & -2.75 \\
Intestine & 205 & 197 & -3.90 \\
Heart & 2287 & 2226 & -2.67 \\
Lung & 2575 & 2599 & 0.93
\end{tabular}

Source: 2009 OPTN/SRTR Annual Report, Table 1.2.
Table 3: Patients on waiting lists at end of year, 2007-2008

\begin{tabular}{|c|c|c|c|c|c|}
\hline \multirow[b]{2}{*}{ Organs } & \multicolumn{4}{|c|}{ End of year } & \multirow{2}{*}{$\begin{array}{c}\text { \% change } \\
\text { in total } \\
(2007- \\
2008)\end{array}$} \\
\hline & $\begin{array}{l}\text { Total } \\
2007\end{array}$ & $\begin{array}{c}\% \\
\text { inactive }\end{array}$ & $\begin{array}{l}\text { Total } \\
2008\end{array}$ & $\begin{array}{c}\% \\
\text { inactive }\end{array}$ & \\
\hline All organs & 96874 & 33 & 100597 & 33 & 3.8 \\
\hline Kidney & 71601 & 32 & 76089 & 33 & 6.3 \\
\hline PTA & 581 & 59 & 581 & 64 & 0.0 \\
\hline PAK & 919 & 75 & 856 & 74 & -6.9 \\
\hline $\begin{array}{l}\text { Kidney- } \\
\text { pancreas }\end{array}$ & 2235 & 40 & 2234 & 45 & 0.0 \\
\hline Liver & 16365 & 25 & 15807 & 23 & -3.4 \\
\hline Intestine & 220 & 24 & 212 & 31 & -3.6 \\
\hline Heart & 2637 & 47 & 2711 & 38 & 2.8 \\
\hline Lung & 2211 & 55 & 2016 & 46 & -8.8 \\
\hline Heart-lung & 105 & 68 & 91 & 64 & -13.3 \\
\hline
\end{tabular}

Source: 2009 OPTN/SRTR Annual Report, Table 1.3, 5.1a-b, 6.1ab, 7.1a-b, 8.1a-b, 9.1a-b, 10.1a-b, 11.1a-b, 12.1a-b, 13.1a-b. PTA = pancreas transplant alone. PAK $=$ pancreas after kidney.

ceiving a subsequent transplant or alternative therapy such as dialysis or resumption of insulin, resulting in lower graft survival rates than corresponding patient survival rates.

Table 6 shows that posttransplant patient and graft survival outcomes have improved over the past decade for almost every organ [Tables $1.11 \mathrm{~b}$ and 1.12b]. Unadjusted 1 -year graft survival for deceased donor kidney recipients improved from $88.8 \%$ to $91.4 \%$. Graft survival after living donor kidney transplant improved $2 \%$. Unadjusted 1year graft survival for deceased donor and living donor liver recipients improved $6 \%$ and $16 \%$, respectively. One-year graft survival after intestine (alone) transplant increased markedly from $50 \%$ in 1998 to $75 \%$ in 2007 . The greatest improvement was seen in heart-lung recipients, for whom 1 -year unadjusted graft survival increased from $54 \%$ in 1998 to $90 \%$ in 2007 . While only PTA transplants showed

Table 4: Unadjusted 1- and 5-year patient survival by organ

\begin{tabular}{lcc}
\hline $\begin{array}{l}\text { Organ } \\
\text { transplanted }\end{array}$ & $\begin{array}{c}\text { 1-year survival } \\
\text { (Txp 2006-2007) }\end{array}$ & $\begin{array}{c}\text { 5-year survival } \\
\text { (Txp 2002-2007) }\end{array}$ \\
\hline Kidney & & \\
$\quad$ Deceased donor & $95.6 \%$ & $81.9 \%$ \\
$\quad$ Living donor & $98.5 \%$ & $91.0 \%$ \\
Pancreas alone & $97.8 \%$ & $88.7 \%$ \\
Pancreas after kidney & $97.0 \%$ & $84.5 \%$ \\
Kidney-pancreas & $95.7 \%$ & $87.2 \%$ \\
Liver & & \\
$\quad$ Deceased donor & $88.4 \%$ & $73.8 \%$ \\
Living donor & $91.0 \%$ & $79.0 \%$ \\
Intestine & $89.3 \%$ & $57.9 \%$ \\
Heart & $88.3 \%$ & $74.9 \%$ \\
Lung & $83.3 \%$ & $54.4 \%$ \\
Heart-lung & $80.6 \%$ & $44.9 \%$ \\
Kidney-liver & $87.4 \%$ & $71.4 \%$ \\
Kidney-heart & $95.8 \%$ & $77.6 \%$ \\
Liver-intestine & $63.3 \%$ & $58.0 \%$ \\
\hline Source: 2009 OPTN/SRTR Ann &
\end{tabular}

Source: 2009 OPTN/SRTR Annual Report, Table 1.13. 
Table 5: Unadjusted 1- and 5-year graft survival by organ

\begin{tabular}{lcc}
\hline $\begin{array}{l}\text { Organ } \\
\text { transplanted }\end{array}$ & $\begin{array}{c}\text { 1-year survival } \\
\text { (Txp 2006-2007) }\end{array}$ & $\begin{array}{c}\text { 5-year survival } \\
\text { (Txp 2002-2007) }\end{array}$ \\
\hline Kidney & & \\
$\quad$ Deceased donor & $91.0 \%$ & $69.3 \%$ \\
$\quad$ Living donor & $96.3 \%$ & $81.4 \%$ \\
Pancreas alone & $75.5 \%$ & $51.5 \%$ \\
Pancreas after kidney & $80.0 \%$ & $53.4 \%$ \\
Kidney-pancreas (kidney) & $92.5 \%$ & $78.6 \%$ \\
Kidney-pancreas (pancreas) & $84.8 \%$ & $73.4 \%$ \\
Liver & & \\
$\quad$ Deceased donor & $84.3 \%$ & $68.4 \%$ \\
$\quad$ Living donor & $86.0 \%$ & $72.9 \%$ \\
Intestine & $78.9 \%$ & $39.6 \%$ \\
Heart & $87.9 \%$ & $73.7 \%$ \\
Lung & $81.6 \%$ & $51.5 \%$ \\
Heart-lung & $80.5 \%$ & $43.1 \%$ \\
Kidney-liver (kidney) & $83.0 \%$ & $64.4 \%$ \\
Kidney-liver (liver) & $83.7 \%$ & $66.0 \%$ \\
Kidney-heart (heart) & $92.6 \%$ & $76.0 \%$ \\
Kidney-heart (kidney) & $88.2 \%$ & $72.0 \%$ \\
Liver-intestine (intestine) & $58.7 \%$ & $53.0 \%$ \\
Liver-intestine (liver) & $58.7 \%$ & $53.4 \%$ \\
\hline
\end{tabular}

Source: 2009 OPTN/SRTR Annual Report, Table 1.13.

lower graft survival in 2007 than in 1998, the graft survival estimates are based on small numbers of transplants and are not statistically significantly different from each other $(p=0.83)$. The statistical significance of each comparison of 1998 survival with 2007 survival is shown in Table 6 by organ type.

Trends in patient survival over the past decade have mirrored those in graft survival, with notable improvements in survival for recipients of every organ type except PTA, PAK and intestine. Trends in patient and graft survival are explored in detail in each of the organ specific articles in this volume of the 2009 Report on the State of Transplantation.

\section{Transplantation at a Glance}

The figure sets accompanying this article (Figures 1-8) provide overviews of the state of transplantation for eight organ groups: kidney, PTA, PAK, liver, intestine, heart, lung and simultaneous pancreas-kidney (SPK) transplantation, which is the most common multi-organ procedure. Because of the small numbers of other multi-organ procedures (e.g. heart-lung transplants), they are excluded from the counts presented here.

\section{Number of transplants and size of active waiting list}

These figures show the size of the active waiting list and the number of transplants performed for each of the past 10 years. The size of the waiting list is best described as a snapshot capturing the number of candidates active on the waiting list on December 31. It does not count those pa-
Table 6: Unadjusted 1-year graft and patient survival by organ (1998 and 2007)

\begin{tabular}{|c|c|c|c|c|}
\hline \multirow[b]{2}{*}{ Graft survival } & \multicolumn{2}{|c|}{$\begin{array}{l}\text { Year of } \\
\text { transplant }\end{array}$} & \multirow[b]{2}{*}{$\%$ change } & \multirow[b]{2}{*}{ p-Value } \\
\hline & 1998 & 2007 & & \\
\hline $\begin{array}{l}\text { Kidney: deceased } \\
\text { donor graft } \\
\text { survival }\end{array}$ & $89 \%$ & $91 \%$ & 3 & $<0.0001$ \\
\hline $\begin{array}{l}\text { Kidney: living donor } \\
\text { graft survival }\end{array}$ & $95 \%$ & $97 \%$ & 2 & $<0.0001$ \\
\hline $\begin{array}{l}\text { Pancreas transplant } \\
\text { alone }\end{array}$ & $78 \%$ & $76 \%$ & -1 & 0.8341 \\
\hline $\begin{array}{l}\text { Pancreas after } \\
\text { kidney }\end{array}$ & $72 \%$ & $82 \%$ & 10 & 0.0302 \\
\hline $\begin{array}{l}\text { Kidney-pancreas: } \\
\text { kidney }\end{array}$ & $91 \%$ & $93 \%$ & 2 & 0.1355 \\
\hline $\begin{array}{l}\text { Kidney-pancreas: } \\
\text { pancreas }\end{array}$ & $83 \%$ & $86 \%$ & 4 & 0.0392 \\
\hline $\begin{array}{l}\text { Liver: deceased } \\
\text { donor graft } \\
\text { survival }\end{array}$ & $80 \%$ & $86 \%$ & 6 & $<0.0001$ \\
\hline $\begin{array}{l}\text { Liver: living donor } \\
\text { graft survival }\end{array}$ & $70 \%$ & $87 \%$ & 16 & 0.0022 \\
\hline Intestine & $50 \%$ & $75 \%$ & 25 & 0.0004 \\
\hline Heart & $85 \%$ & $88 \%$ & 3 & 0.0006 \\
\hline Lung & $75 \%$ & $80 \%$ & 5 & 0.0115 \\
\hline \multirow[t]{2}{*}{ Heart-lung } & $54 \%$ & $90 \%$ & 36 & 0.0001 \\
\hline & \multicolumn{2}{|c|}{$\begin{array}{l}\text { Year of } \\
\text { transplant }\end{array}$} & & \\
\hline Patient survival & 1998 & 2007 & $\%$ change & $\mathrm{p}$-Value \\
\hline $\begin{array}{l}\text { Kidney: deceased } \\
\text { donor patient } \\
\text { survival }\end{array}$ & $95 \%$ & $96 \%$ & 1 & 0.0055 \\
\hline $\begin{array}{l}\text { Kidney: living donor } \\
\text { patient survival }\end{array}$ & $98 \%$ & $99 \%$ & 1 & 0.0015 \\
\hline $\begin{array}{l}\text { Pancreas transplant } \\
\text { alone }\end{array}$ & $98 \%$ & $98 \%$ & 0 & 0.9320 \\
\hline $\begin{array}{l}\text { Pancreas after } \\
\text { kidney }\end{array}$ & $94 \%$ & $97 \%$ & 3 & 0.2472 \\
\hline Kidney-pancreas & $94 \%$ & $97 \%$ & 3 & 0.0093 \\
\hline $\begin{array}{l}\text { Liver: deceased } \\
\text { donor patient } \\
\text { survival }\end{array}$ & $86 \%$ & $89 \%$ & 3 & $<0.0001$ \\
\hline $\begin{array}{l}\text { Liver: living donor } \\
\text { patient survival }\end{array}$ & $80 \%$ & $91 \%$ & 11 & 0.0173 \\
\hline Intestine & $67 \%$ & $78 \%$ & 11 & 0.0995 \\
\hline Heart & $86 \%$ & $89 \%$ & 3 & 0.0006 \\
\hline Lung & $77 \%$ & $82 \%$ & 6 & 0.0016 \\
\hline Heart-lung & $57 \%$ & $90 \%$ & 34 & 0.0003 \\
\hline
\end{tabular}

Source: 2009 OPTN/SRTR Annual Report, Table 1.11b, 1.12b.

tients who were transplanted, listed or removed during the preceding 12 months. The number of transplants includes all transplants performed over the year.

Because of these different methods of counting, for some organs (e.g. lung), the number of transplants performed during a certain year may exceed the number of people awaiting a transplant on the last day of the same 
A

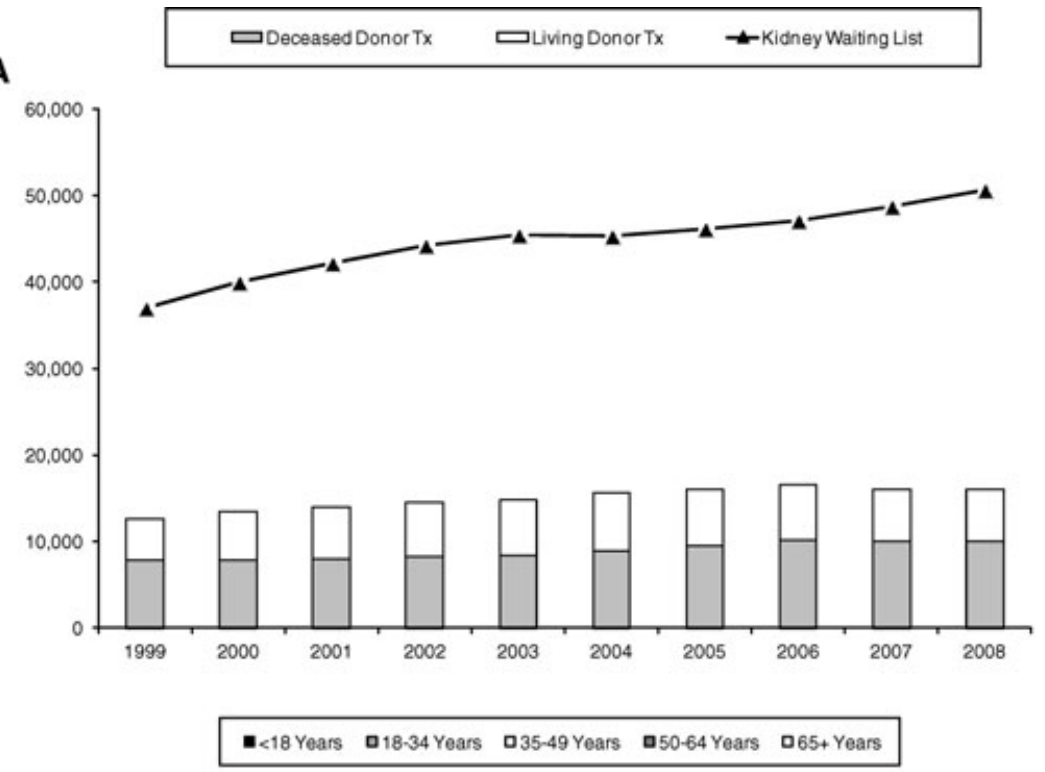

B

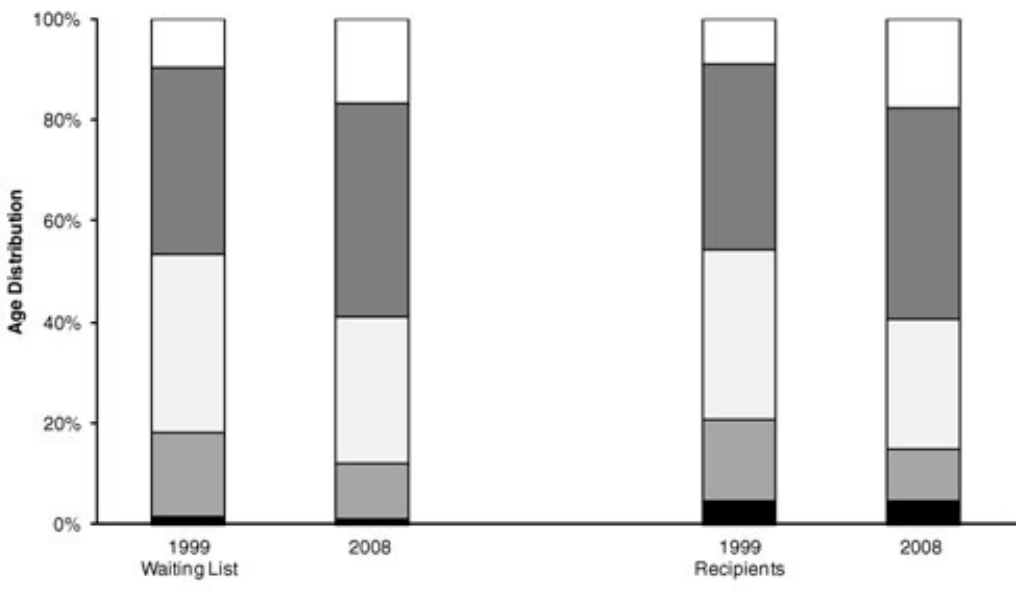

- Patient Sunvival aGraft Sunival

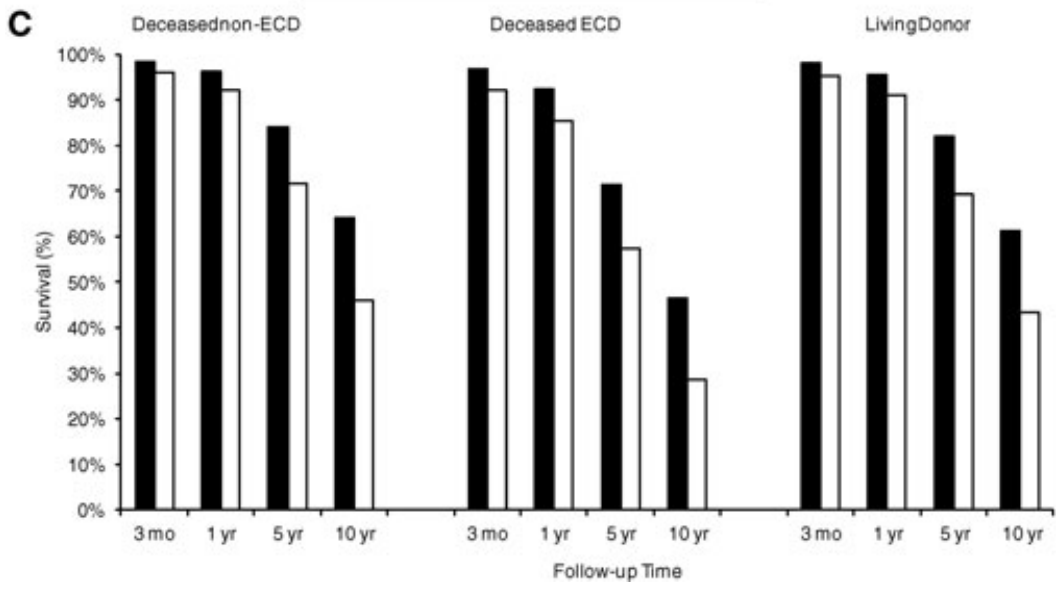

Figure 1: Kidney transplantation at a glance. (A) Number of transplants and size of active waiting list. There was a very large gap between the number of patients waiting for a transplant and the number receiving a transplant. This gap widened over the decade, meaning that the waiting times from listing to transplant continued to increase. The number of living donor transplants grew until 2004, while the number of deceased donor transplants continued to rise gradually until 2006. Source: 2009 OPTN/SRTR Annual Report, Tables 1.7, 5.1a. (B) Age distribution of recipients and active waiting list. In 2008, older candidates (age $>50$ years) made up a much larger fraction of patients actively awaiting an organ than a decade earlier. The same pattern was observed for transplant recipients. Source: 2009 OPTN/SRTR Annual Report, Tables 5.1a, 5.4a, 5.4b, 5.4c. (C) Unadjusted Patient and Graft Survival. Fiveyear patient survival percentages (based on transplants during 2002-2007) and 10-year patient survival (based on transplants during 1997-2007) were clearly higher for recipients of living donor organs than for those of deceased donor organs. Similarly, living donor organs had the highest 5- and 10-year graft survival. Source: 2009 OPTN/SRTR Annual Report, Tables 5.10a, 5.10b, 5.10d, 5.14a, 5.14b, 5.14d. 


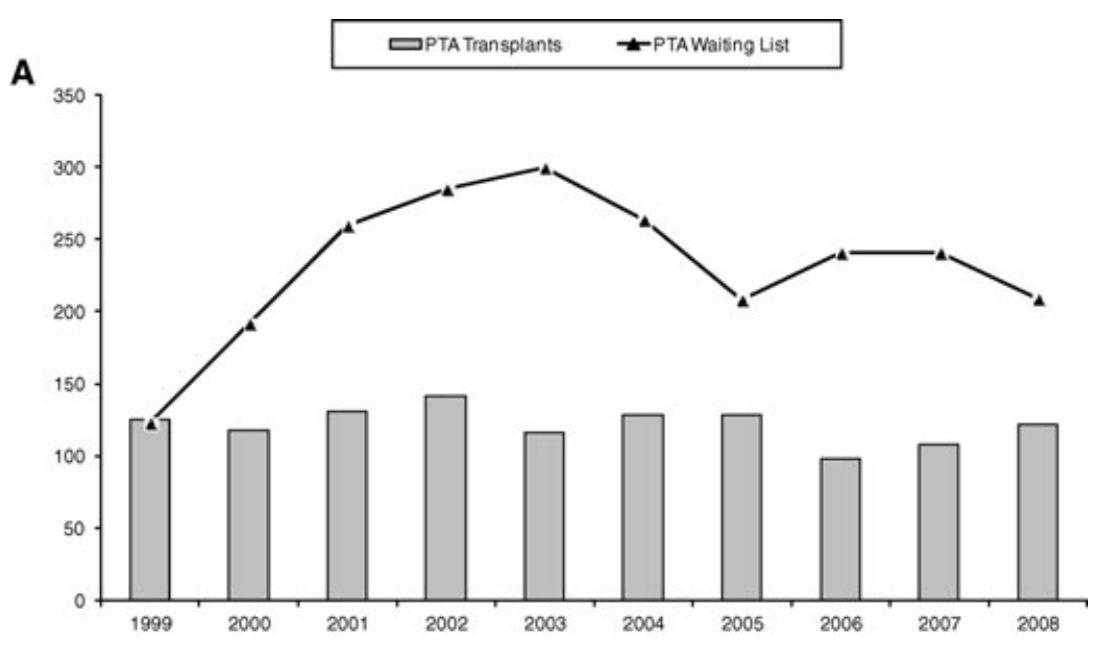

Figure 2: Pancreas transplantation alone (PTA) at a glance. (A) Number of transplants and size of active waiting list. The number of patients on the waiting list for a pancreas transplant alone decreased after 2003 and has remained at pre-2001 levels. The number of PTA transplants per year was relatively stable. Source: 2009 OPTN/SRTR Annual Report, Tables 1.7, 6.1a. (B) Age distribution of recipients and active waiting list. For PTA, more pediatric candidates were wait-listed and more received a transplant in 2008 than in 1999, although the absolute numbers are small. At the same time, the fraction of recipients over age 50 years grew. Pediatric diabetic patients rarely have kidney failure before age 18 years, but they are candidates for PTA. Source: 2009 OPTN/SRTR Annual Report, Tables 6.1a, 6.4. (C) Unadjusted patient and graft survival. The 5-year patient survival rate for PTA transplants was $89 \%$. Graft survival was considerably lower, especially at 5 and 10 years posttransplant. Source: 2009 OPTN/SRTR Annual Report, Tables $6.10,6.14$.
- $<18$ Years 0 18-34 Years 035-49 Years 0 50-64 Years 065+Years

B

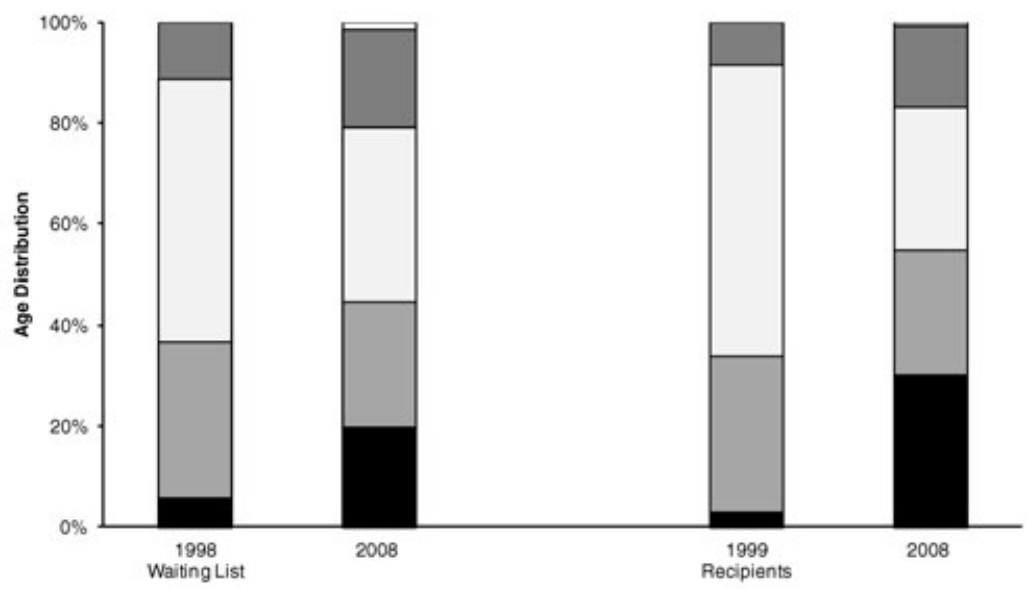

Deceased Donor

C

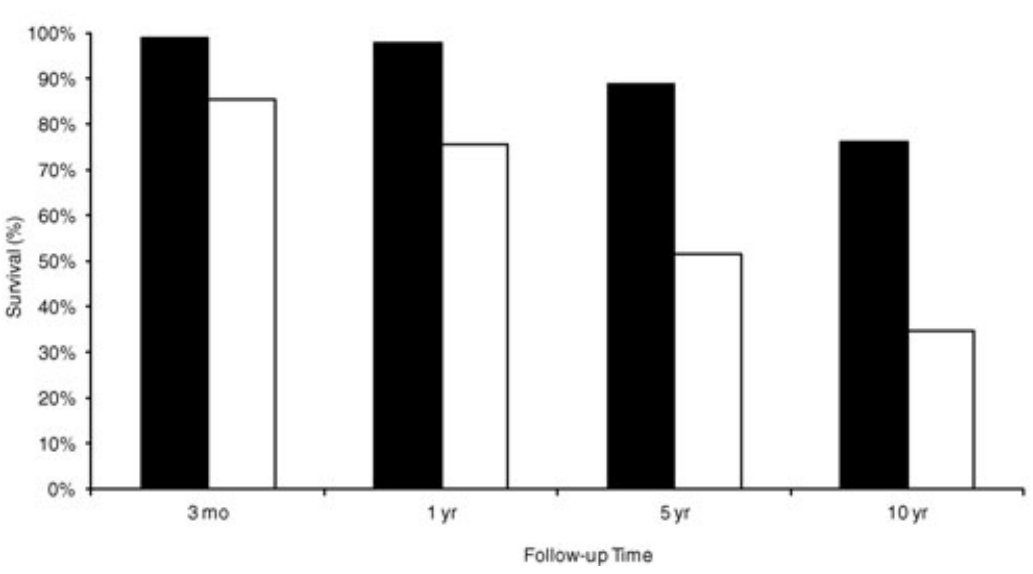




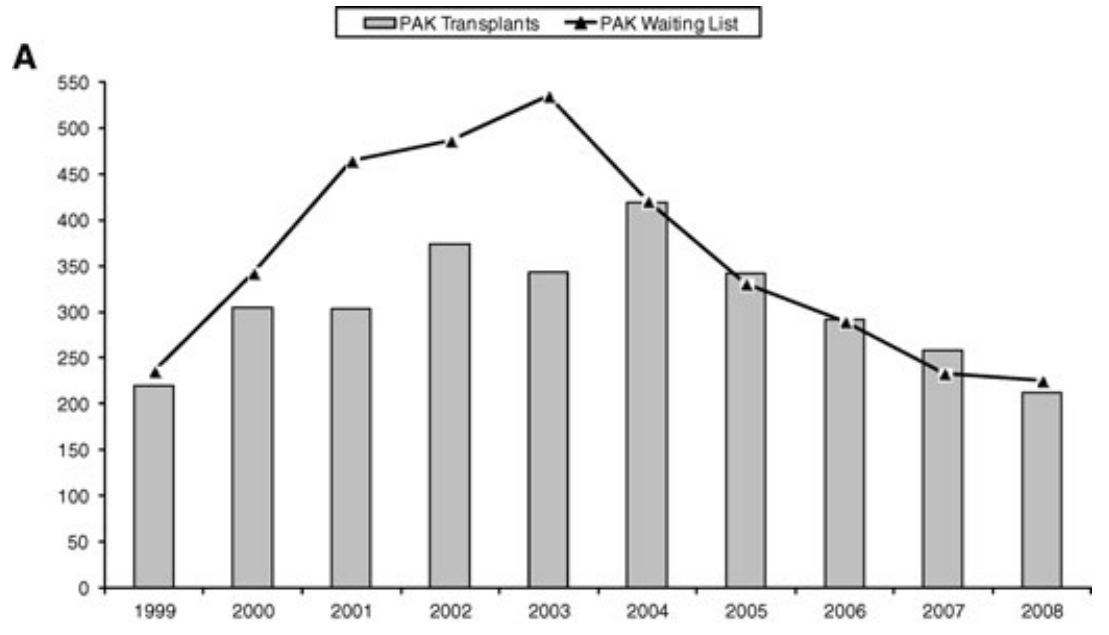

- $<18$ Years $\mathbf{0 1 8 - 3 4}$ Years $\mathbf{0} 35-49$ Years $\mathbf{0}$ 50-64 Years a65+Years

B

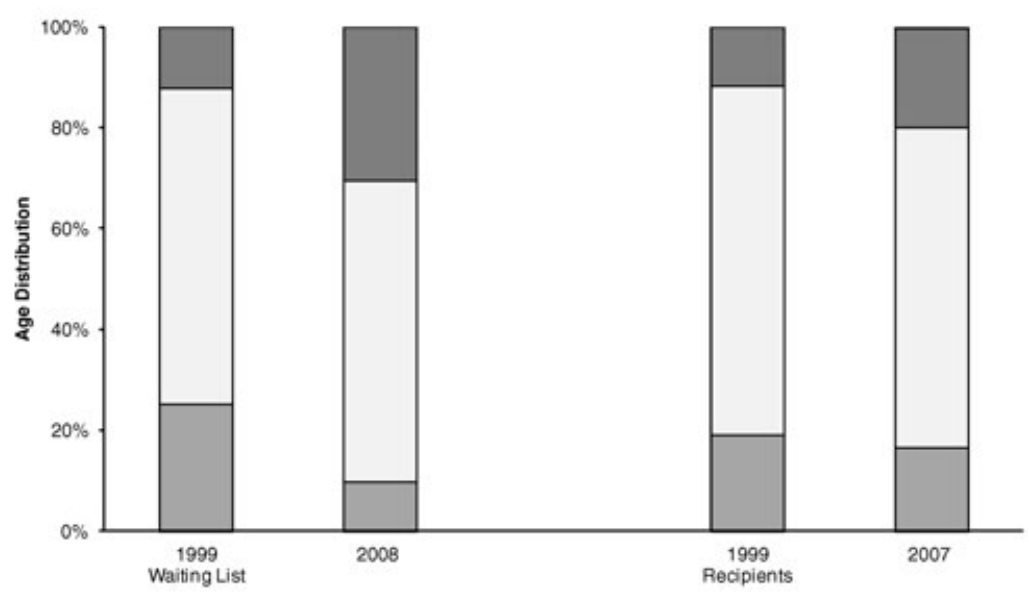

Deceased Donor

- Pasient Survival aGratt Survival

C

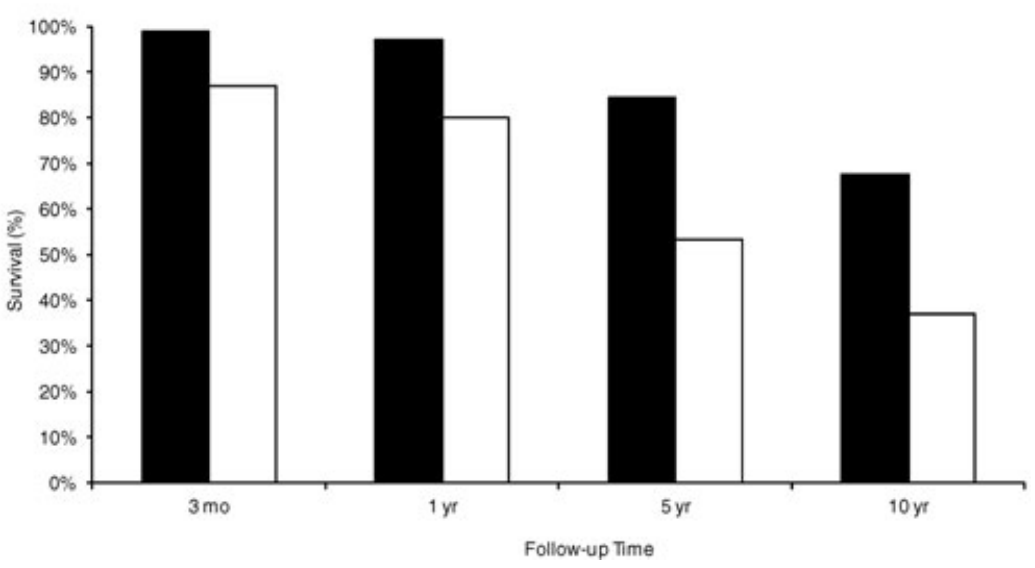

Figure 3: Pancreas after kidney (PAK) transplantation at a glance. (A) Number of transplants and size of active waiting list. The number of patients on the waiting list for a PAK transplant has decreased since 2003. The number who received a transplant has matched the number of candidates each year since 2004. The number of PAK transplants has decreased from its highest level of the decade in 2004. Source: 2009 OPTN/SRTR Annual Report, Tables 1.7, 7.1a. (B) Age distribution of recipients and active waiting list. For PAK, a higher proportion of wait-listed and transplanted patients were over 50 years old in 2008 than in 1999. At the same time, a smaller proportion of candidates and recipients were in the 18-34 year age group. (Since recipients were mostly type 1 diabetics, the ages below 18 and above 65 years were virtually unrepresented.) Source: 2009 OPTN/SRTR Annual Report, Tables 7.1a, 7.4. (C) Unadjusted patient and graft survival. For PAK transplants, patient survival was similar to that seen for simultaneous kidney-pancreas transplant recipients. Five-year patient survival was $85 \%$. Pancreas graft survival after PAK was considerably lower. Source: 2009 OPTN/SRTR Annual Report, Tables 7.10, 7.14 . 


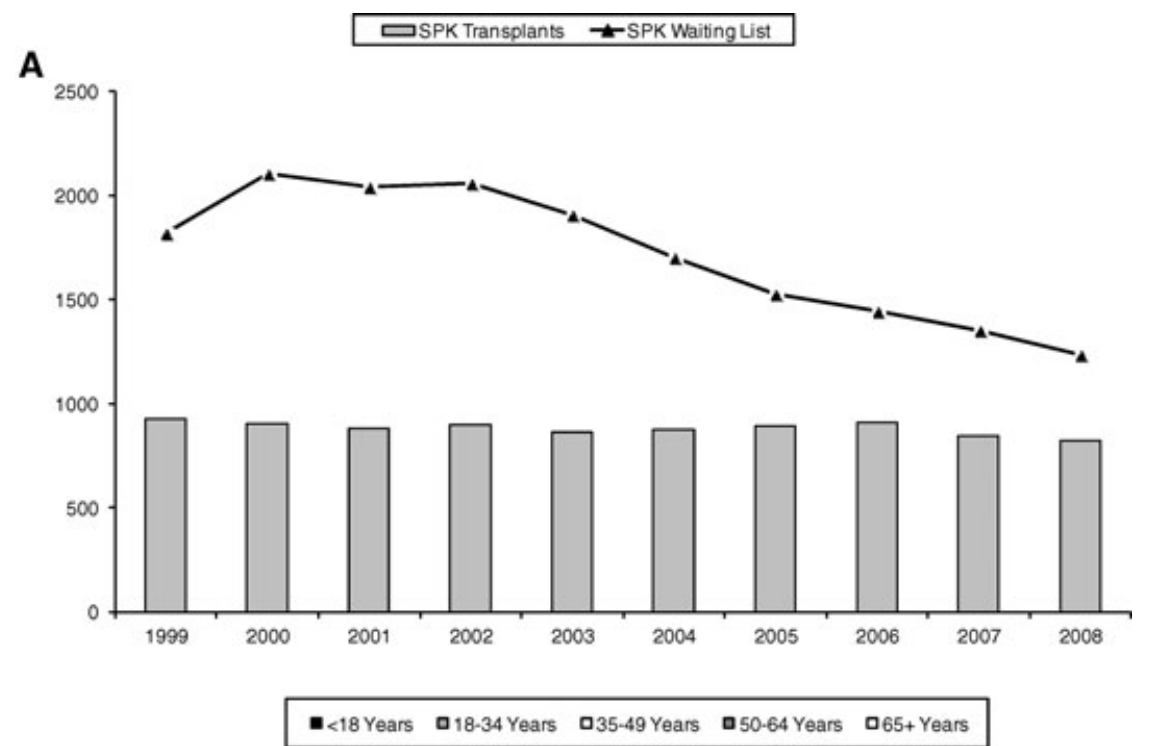

Figure 4: Simultaneous pancreaskidney (SPK) transplantation at a glance. (A) Number of transplants and size of active waiting list. SPK accounts for the majority of all pancreas transplants. Numbers of this procedure were stable over the decade. The gap between the number of patients waiting for a transplant and the number receiving a transplant has dropped substantially since 2000 . Source: 2009 OPTN/SRTR Annual Report, Tables 1.7, 8.1a. (B) Age distribution of recipients and active waiting list. For SPK transplantation, patients over age 50 years made up greater fractions of both candidates and recipients in 2007 than in 1998. At the same time, smaller proportions of candidates and recipients were in the 18-34 year age group. (Since recipients were mostly type 1 diabetics, the ages below 18 and above 65 years were virtually unrepresented.) Source: 2009 OPTN/SRTR Annual Report, Tables 8.1a, 8.4. (C) Unadjusted patient and graft survival. Patient survival has improved for SPK recipients in recent years. Five- and 10 -year patient survival was $87 \%$ and $71 \%$, respectively. Graft survival is shown separately for the pancreas graft and the kidney graft of each SPK transplant. Source: 2009 OPTN/SRTR Annual Report, Tables 8.10, 8.14.
B

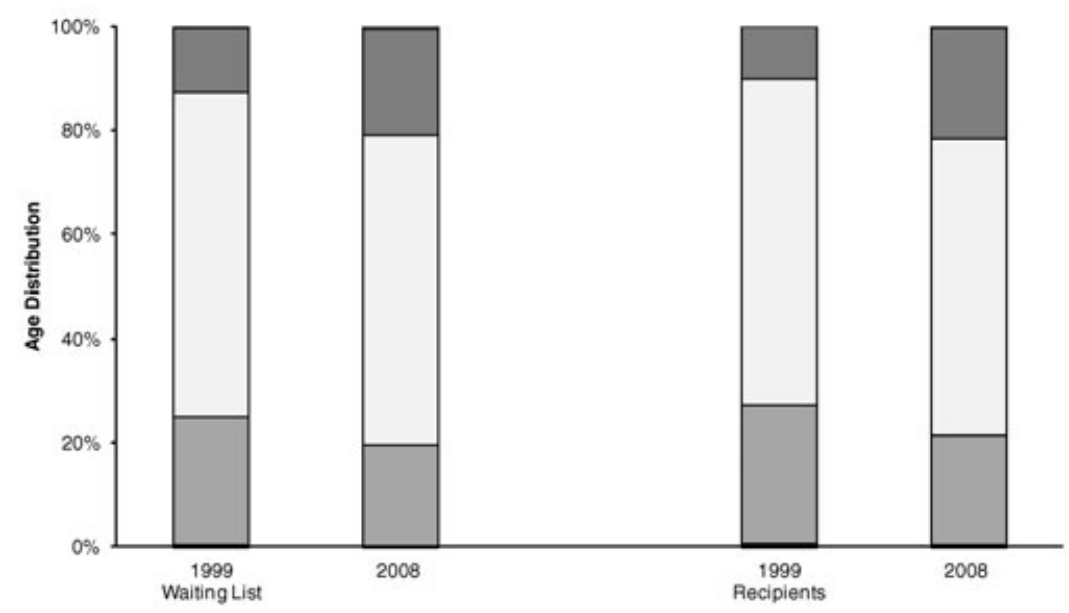

Deceased Donor

- Patient Survival aGraft Survival (Kidney) $\quad$ a Graft Survival (Pancreas)

C

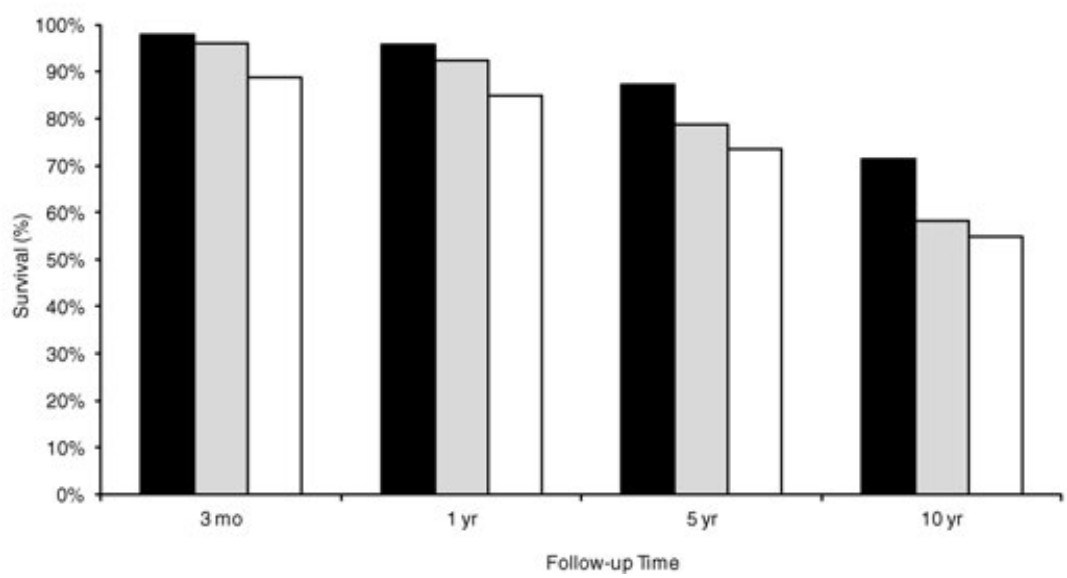




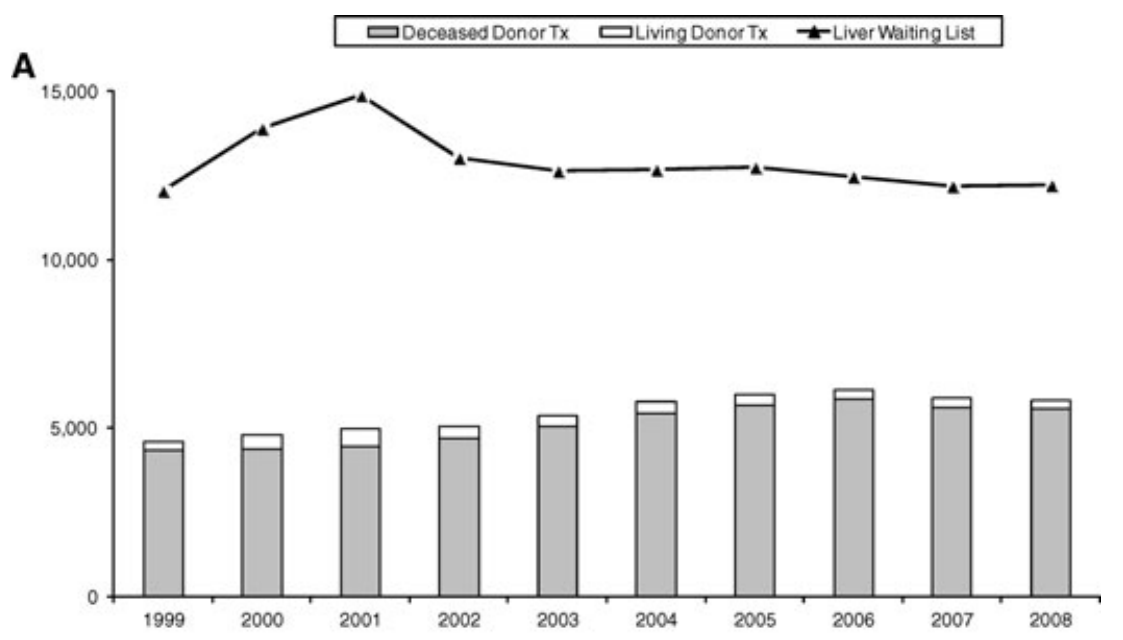

- $<18$ Years a 18-34 Years a 35-49 Years a 50-64 Years 065+ Years

B

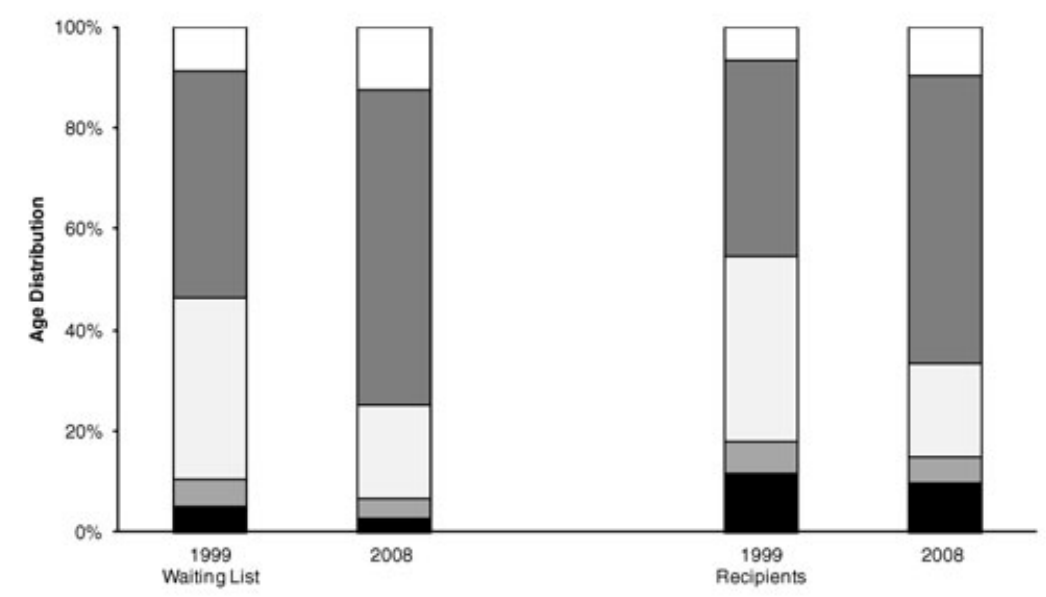

- Patient Survival aGraft Survival

C

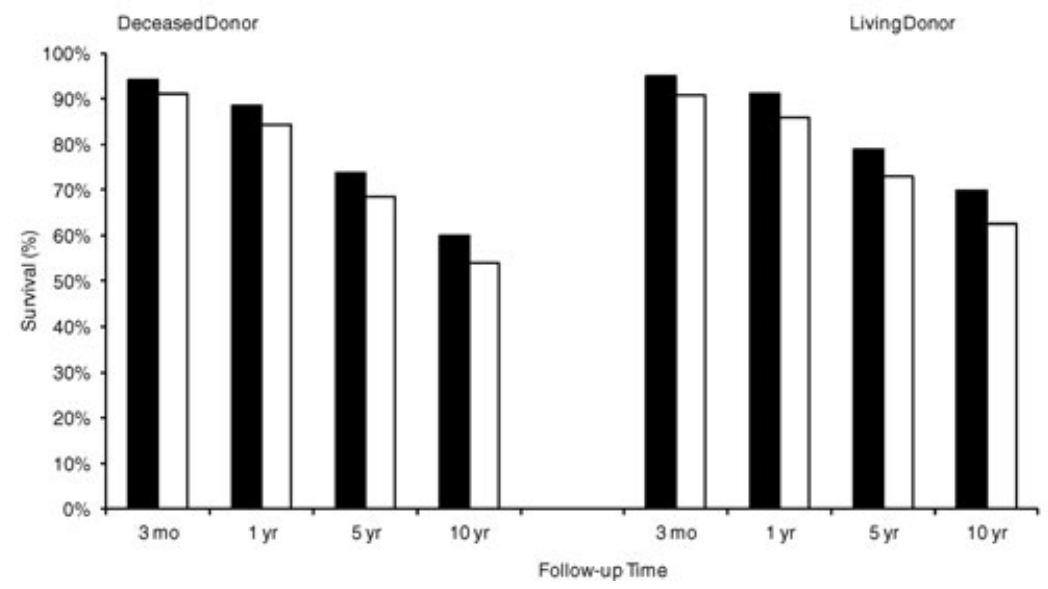

Figure 5: Liver transplantation at a glance. (A) Number of transplants and size of active waiting list. The number of patients awaiting a liver transplant at year-end peaked in 2001; this is clearly related to the introduction of the MELD/PELD allocation system in 2002. The number who received a deceased donor liver transplant has gradually increased, reaching a peak in 2006. The gap between the numbers of candidates and recipients has been slowly shrinking since 2002. Source: 2009 OPTN/SRTR Annual Report, Tables 1.7, 9.1a, 9.1b. (B) Age distribution of recipients and active waiting list. The numbers of candidates and recipients age 35-49 years remained fairly constant over the decade, but the age group's proportion by both measures declined. Recipients included transplants from both living and deceased donors. Source: 2009 OPTN/SRTR Annual Report, Tables 9.1a, 9.4a, 9.4b. (C) Unadjusted patient and graft survival. Patient survival in recent years has been improving for both deceased donors and living donors, with $74 \%$ and $79 \%$ of patients, respectively, alive 5 years following transplantation. Patient survival was higher than graft survival because of the opportunity for repeat liver transplantation in the event of graft failure. Source: 2009 OPTN/SRTR Annual Report, Tables 9.10a, 9.10b, 9.14a and 9.14b. 


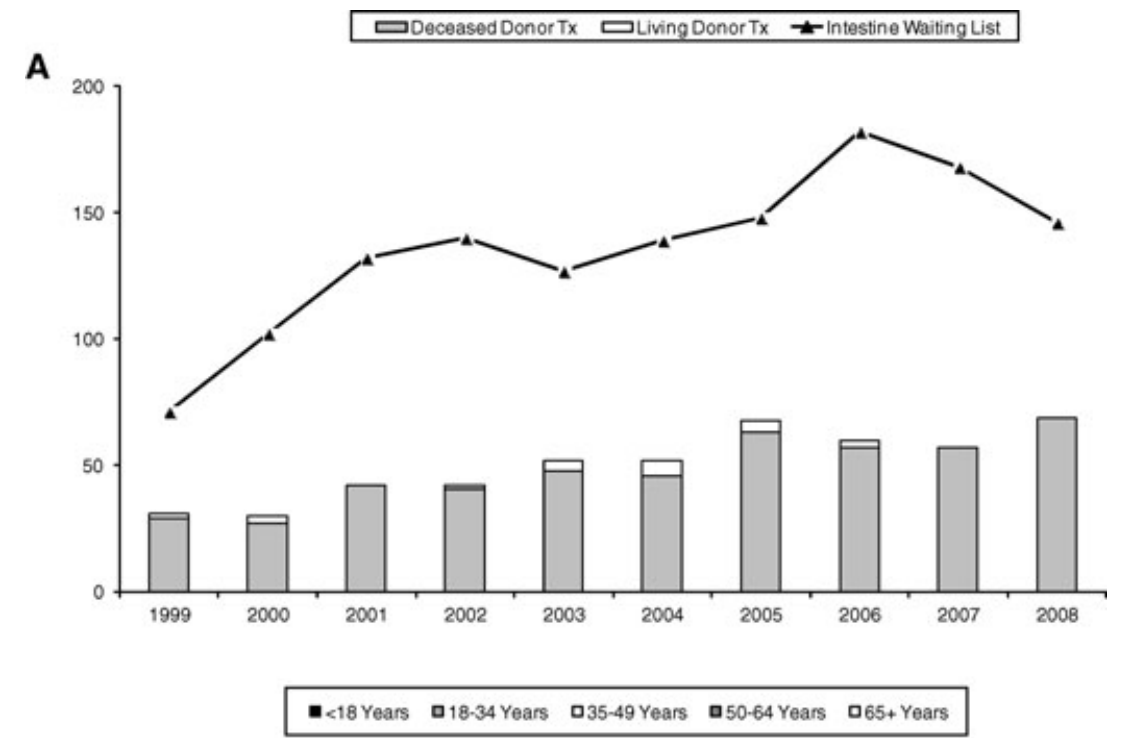

B

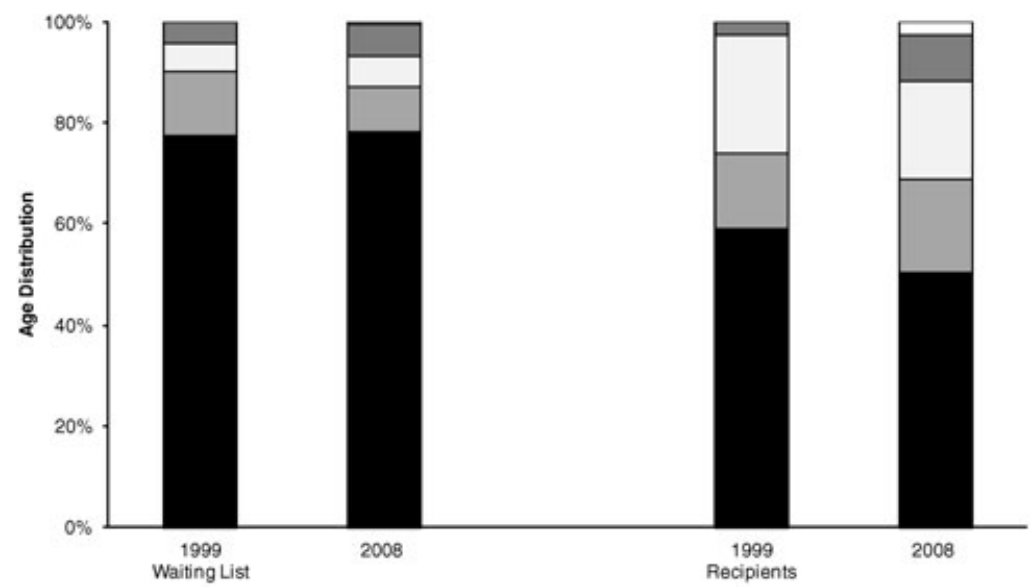
more than doubled between 1999 and 2008 despite the fact that the number of patients on the waiting list has declined since 2006. Source: 2009 OPTN/SRTR Annual Report, Tables 1.7, 10.1a. (B) Age distribution of recipients and active waiting list. About $77 \%$ of intestine candidates were in the pediatric age group in 1999 compared with $78 \%$ in 2008. Adults made up a greater portion of recipients than candidates. Source: 2009 OPTN/SRTR Annual Report, Tables 10.1a, 10.4. (C) Unadjusted patient and graft survival. One-year patient survival was $78 \%$ in 2008. Survival at 5 years was $57 \%$. Graft survival was lower, since recipients may receive parenteral alimentation or retransplantation after graft failure. Source: 2009 OPTN/SRTR Annual Report, Tables $10.10,10.14$.

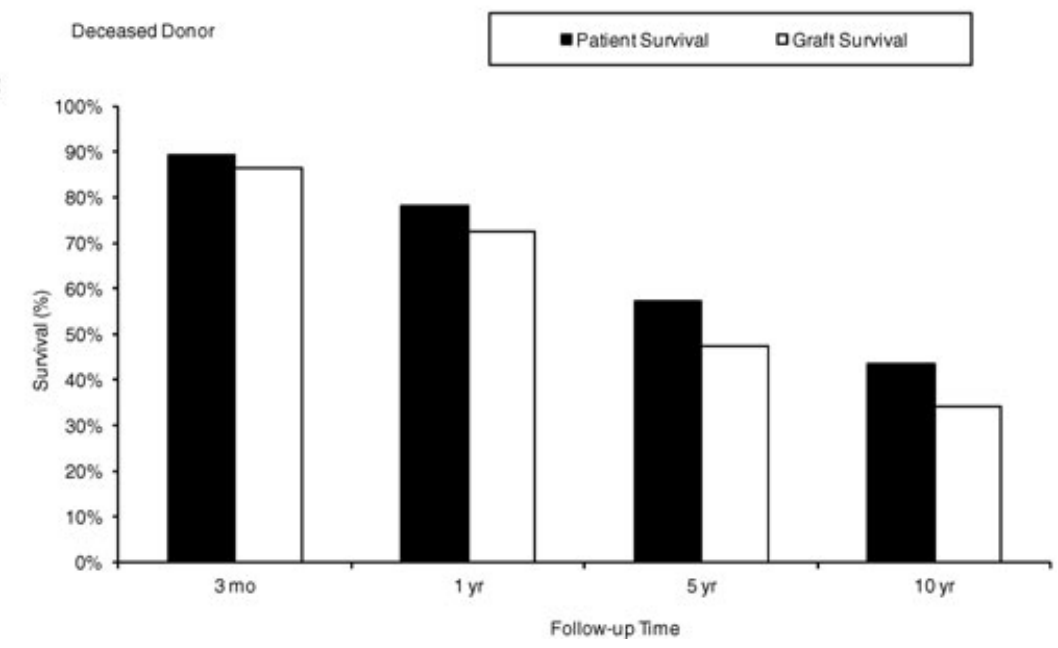




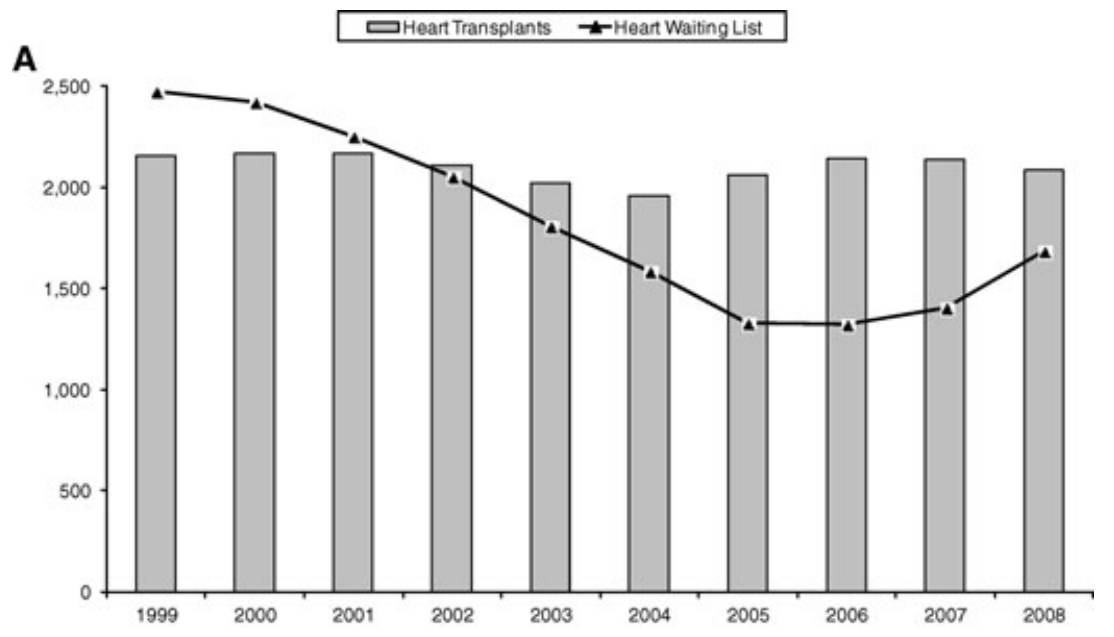

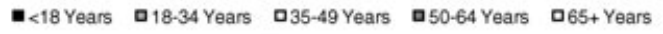

B

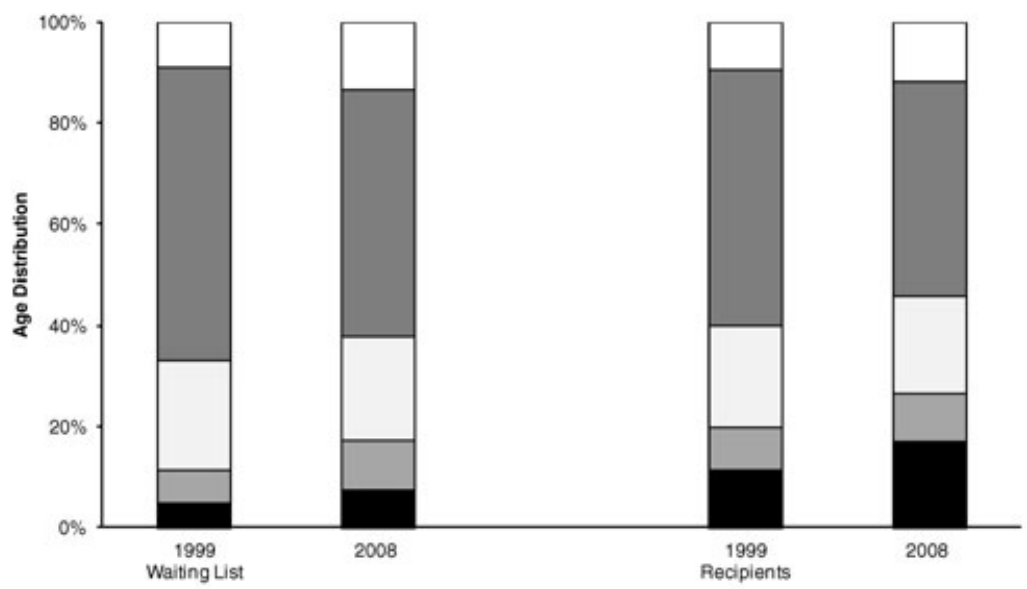

Deceased Donor

- PasentSurvival aGraft Survival

C

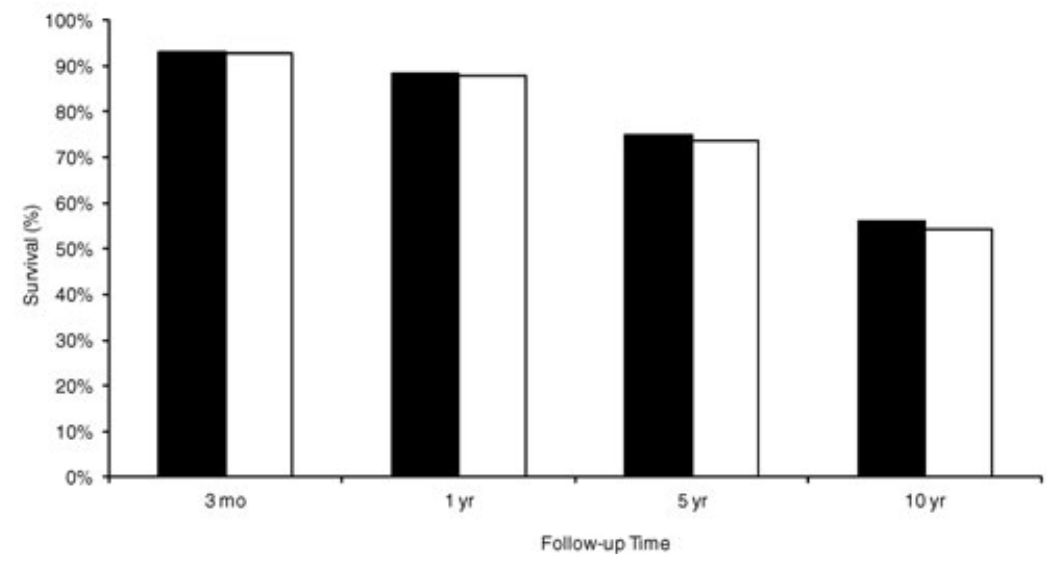

Figure 7: Heart transplantation at a glance. (A) Number of transplants and size of active waiting list. The number of heart transplants has remained stable over the past decade. The number of patients awaiting a heart decreased steeply from 2000 to 2005, likely reflecting improvements in medical and surgical therapy for end-stage heart failure. Source: 2009 OPTN/SRTR Annual Report, Tables 1.7, 11.1a. (B) Age distribution of recipients and active waiting list. Trends in the age distribution of wait-listed candidates show that the proportions (and absolute numbers) of patients younger than 35 and older than 64 years increased, while the age group 35-64 years has decreased. The trend in transplant recipient age showed a similar pattern, although the ages below 35 years had greater representation than on the waiting list. Source: 2009 OPTN/SRTR Annual Report, Tables 11.1a, 11.4. (C) Unadjusted patient and graft survival. Patient survival improved in recent years for heart recipients. At 1, 5 and 10 years following heart transplantation, $88 \%, 75 \%$ and $56 \%$ of patients, respectively, were alive. Graft survival was very similar to patient survival because very few patients receive a second heart transplant. Source: 2009 OPTN/SRTR Annual Report, Tables 11.10, 11.14. 


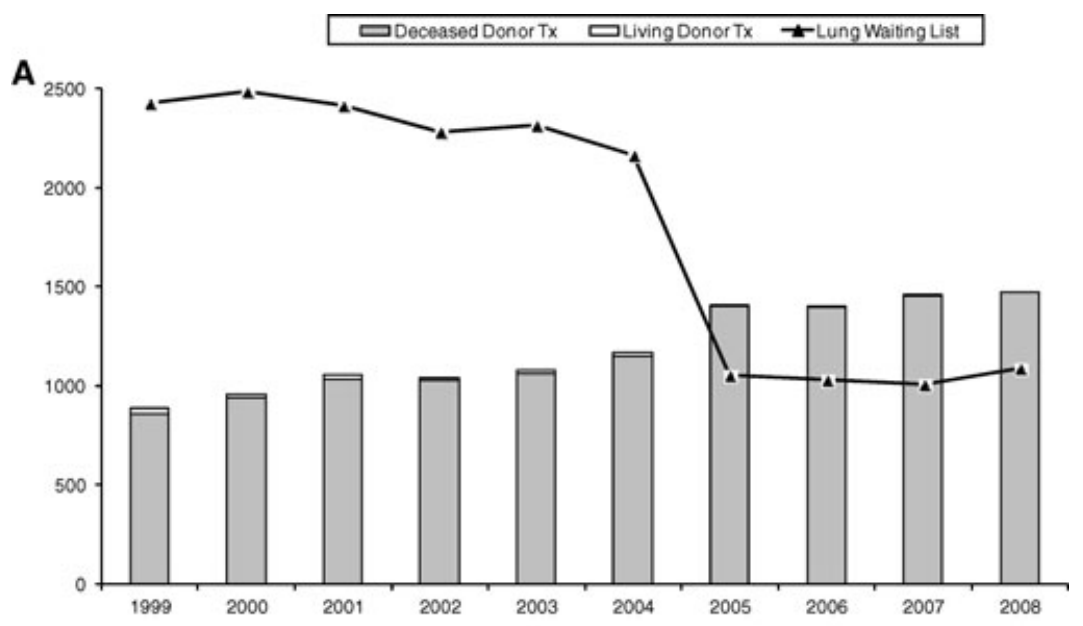

Figure 8: Lung transplantation at a glance. (A) Number of transplants and size of active waiting list. The number of lung transplants has increased in the last 2 years. The number of patients awaiting a transplant dropped steeply in 2005 after a stable pattern during the prior 6 years. This sharp reduction is largely attributable to a major change in allocation policy, which is now based on medical urgency and calculated transplant benefit rather than waiting time. Source: 2009 OPTN/SRTR Annual Report, Tables 1.7, 12.1a. (B) Age distribution of recipients and active waiting list. The lung waiting list showed a mixed trend in age distribution, with increasing percentages of candidates older than 50 years and decreasing percentages younger than 18 years. Candidates $18-49$ years old showed a corresponding reduction in the percentage of the waiting list. The pattern for transplant recipients showed a similar increase for ages 50 years and above and a decrease in percentages for younger ages, including children. Source: 2009 OPTN/SRTR Annual Report. Tables 12.1a, 12.4a, 12.4b. (C) Unadjusted patient and graft survival. Patient survival has been improving in recent years. At 1 year following deceased donor lung transplantation, $84 \%$ of patients were alive. Graft survival was very similar to patient survival because very few lung retransplants are performed. Source: 2009 OPTN/SRTR Annual Report, Tables 12.10a, 12.10b, 12.14a, 12.14b.

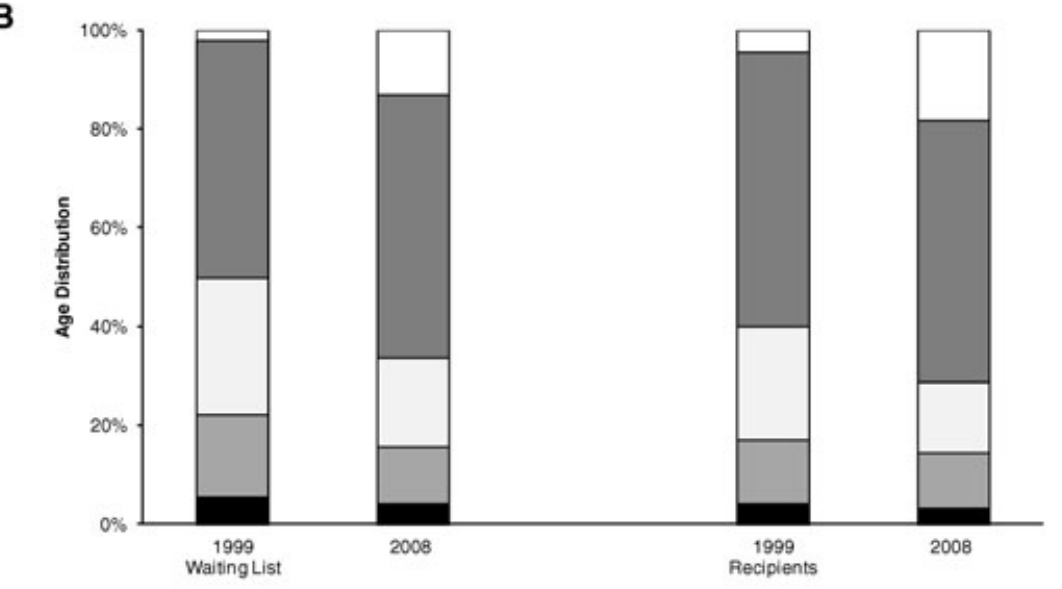

Deceased Donor

- Patent Surviva

a Graft Survival

C

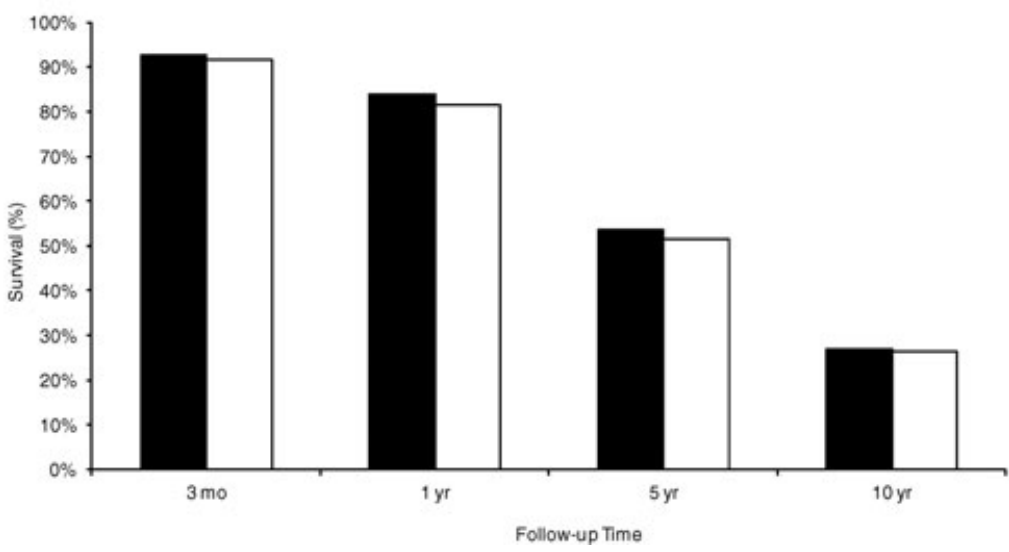


year. The narrowing gap between waiting list size and number of transplants can be explained, in some cases, by changes in allocation policy and wait-listing practices.

\section{Unadjusted patient and graft survival}

The summary figures show survival of transplant recipients (patient survival) and continued function of the transplanted organ (graft survival) at 3 months, 1 year, 5 years and 10 years following transplantation. These results are based on analysis of the most recent cohorts, with sufficient follow-up time for data collection and ascertainment of events.

\section{The Articles in the 2009 Report on the State of Transplantation}

This report first presents 'Organ Donation and Utilization in the United States, 1999-2008' (2). Five organ-specific articles then follow: 'Kidney and Pancreas Transplantation in the United States, 1999-2008: The Changing Face of Living Donation' (3), 'Liver Transplantation in the United States, 1999-2008' (4), 'Intestine and Multi-Visceral Transplantation in the United States, 1999-2008' (5), 'Heart Transplantation in the United States, 1999-2008' (6) and 'Lung Transplantation in the United States, 1999-2008' (7). Each piece provides detailed updates regarding donation, waiting time, allocation, posttransplant outcomes and the demographics of candidates and recipients. These articles are intended to supplement the 2009 OPTN/SRTR Annual Report coverage of 10 -year trends, with reporting on recent changes in allocation policy, clinical practice and other areas relevant to the transplantation of different organ types.

This year's report concludes with three special-focus articles that closely examine issues of recent interest to the transplant community. 'Geographic Variation in EndStage Renal Disease Incidence and Access to Kidney Transplantation' (8) investigates differences in organ donation rates and how the density of end-stage renal disease (ESRD) in the general population affects access to the kidney transplant waiting list and successful kidney transplantation. 'DonorNet and the Effects on Organ Donation' (9) discusses the impact of DonorNet on organ utilization, focusing on ischemia time of transplanted organs and graft outcomes. 'Transplant Outcomes Among Minorities Between 1999 and 2008: Determinants of Kidney Allograft Survival' (10) assesses trends in minority access to care and outcomes for kidney and heart transplantation by race/ethnicity category, and examines specific determinants of kidney transplant outcomes. Each article includes special analyses conducted by the SRTR, address- ing topics that are both timely and pertinent because of their implications for policy and clinical practice.

\section{Acknowledgments}

Disclaimer: The Scientific Registry of Transplant Recipients is funded by contract number 234-2005-37009C from the Health Resources and Services Administration, US Department of Health and Human Services. The views expressed herein are those of the authors and not necessarily those of the US government. This is a US government-sponsored work. There are no restrictions on its use. This study was approved by HRSA's SRTR project officer. HRSA has determined that this study satisfies the criteria for the IRB exemption described in the 'Public Benefit and Service Program' provisions of 45 CFR 46.101 (b) (5) and HRSA Circular 03. This paper was edited by Heather Van Doren of the Arbor Research Collaborative for Health.

\section{Conflict of Interest Statement}

The authors declare no conflicts of interest.

\section{References}

1. Leichtman A, Cohen D, Keith D, O'Connor K, Goldstein M, McBride V. Kidney and pancreas transplantation in the United States, 19972006: The HRSA breakthrough collaboratives and the 58 DSA challenge. Am J Transplant 2008; 8(4 Pt 2): 946-957.

2. Klein AS, Messersmith EE, Ratner LE, Kochik R, Baliga PK, Ojo AO. Organ donation and utilization in the United States, 1999-2008. Am J Transplant 2010: 10(4 Pt 2): 973-986.

3. Axelrod DA, McCullough KP, Brewer ED, Becker BN, Segev DL, Rao PS. Kidney and pancreas transplantation in the United States, 1999-2008: The changing face of living donation. Am J Transplant 2010: 10(4 Pt 2): 987-1002.

4. Thuluvath PJ, Guidinger MK, Fung JJ, Johnson LB, Rayhill SC, Pelletier SJ. Liver transplantation in the United States, 1999-2008. Am J Transplant 2010: 10(4 Pt 2): 1003-1019.

5. Mazariegos GV, Steffick DE, Farmer D, Fryer J, Grant D, Langnas A, Magee JC. Intestine and multi-visceral transplantation in the United States, 1999-2008. Am J Transplant 2010: 10(4 Pt 2): 10201034.

6. Johnson MR, Meyer KH, Haft J, Kinder D, Webber SA, Dyke DB. Heart transplantation in the United States, 1999-2008. Am J Transplant 2010: 10(4 Pt 2): 1035-1046.

7. Yusen RD, Shearon TH, Qian Y, Kotloff R, Barr ML, Sweet S, Dyke DB, Murray S. Lung transplantation in the United States, 19992008. Am J Transplant 2010: 10(4 Pt 2): 1047-1068.

8. Mathur AK, Ashby VB, Sands RL, Wolfe RA. Geographic variation in end-stage renal disease incidence and access to kidney transplantation. Am J Transplant 2010: 10(4 Pt 2): 1069-1080.

9. Gerber DA, Arrington CJ, Taranto SE, Baker T, Sung RS. DonorNet and the effects on organ donation. Am J Transplant 2010: 10(4 Pt 2): 1081-1089.

10. Fan PY, Ashby VB, Fuller DS, Boulware LE, Kao A, Norman SP, Randall HB, Young C, Kalbfleisch JD, Leichtman AB. Transplant outcomes among minorities between 1999 and 2008: Determinants of kidney allograft survival. Am J Transplant 2010: 10(4 Pt 2): 1090-1107. 